\title{
THE DESIGN OF THE RF CAVITY FOR THE HEAVY ION STORAGE RING
} FOR ATOMIC PHYSICS*

Oak Ridge National Laboratory, Post Office Box 2008, Oak Ridge, Tennessee $37834-6368$

An If cavity and drive system have been designed for the proposed "Heavy Ion Storage Ring for Atomic Physics," HISTRAP, at Oak Ridge. A peak accelerating voltage of $2.5 \mathrm{kV}$ per turn is required with a continuous tuning range from $200 \mathrm{kHz}$ through $2.7 \mathrm{MHz}$. A single-gap, half-wave resonant configuration is used with biased ferrite tuning. The cavity structure is completely outside of the beam line/vacuum enclosure except for a single of window that serves as an accelerating gap. Physical separation of the cavity and beam line permits in situ yacuum baking of the beam line components at $300^{\circ} \mathrm{C}$. A prototype cavity was designed, built, and tested. [1] Development of frequency synthesizer and tuner control circuitry is under way.

\section{DISCLAIMER}

\begin{abstract}
This report was prepared as an account of work sponsored by an agency of the Uniter States Government. Neither the United States Government nor any agency thereof, nor any of their employees, makes any warranty, express or implied, or assumes any legal liability or responsibility for the accuracy, completeness, or usefulness of any information, apparatus, product, or process disclosed, or represents that its use would not infring : privately owned rights. Reference herein to any specific commercial product, process, or service by trade name, trademark, manufacturer, or otherwise does not necessarily constitute or imply its endorsement, recommendatinn, or favoring by the United States Government or any agency thereof. The views and opinions of authors expressed herein do not necessarily state or reflect those of the United States Government or any agency thereof.
\end{abstract}

* Research sponsored by the U.S. Department of Energy under contract DE-AC05-84OR21400 with Martin Marietta Energy Systems, Inc.

1 In collaboration with D. T. Dowling and D. K. Olsen, Physics Division, Oak Ridge National Laboratory. 


\section{Introduction}

HISTRA.P [2] is a proposed $46.8-\mathrm{m}$ circumference synchrotron-coolerstorage ring optimized for advanced atomic physics research. It is injected with heavy ions from either the Holifield Heavy Ion Research Facility (HHIRF) 25-MV tandem accelerator or a dedicated $14.5 \cdot \mathrm{GHz}$ ECR source via an 0.25 MeV/nucleon RFQ linac. Prototypes of major components of HISTRAP have been designed, fabricated, assembled, and tested. Included are an rf cavity with drive system, a dipole magnet and field mapping facility, [3] and a beam line section which has been pumped to a vacuum of $4 \times 10^{-12}$ Torr. [4] A plan view of HISTRAP is shown in Fig. 1 and some general machine parameters are listed in Table 1.

In the standard high-current operating mode, heavy ions from the iandem accelerator are injected into HISTRAP with a magnetic rigidity of about $1.0 \mathrm{Tm}$ and with circulation frequencies between $1.0 \mathrm{MHz}$ for ${ }^{12} \mathrm{C}^{6+}$ and $0.38 \mathrm{MHz}$ fcr $238 \mathrm{U}^{43+}$. These ions are either accelerated to a maximum magnetic rigidity of 2.67 Tm with circulation frequencies between $2.7 \mathrm{MHz}$ and $1.0 \mathrm{MHz}$, or deceierated to a minimum magrietic rigidity of $0.10 \mathrm{Tm}$ with circulation frequencies between $0.10 \mathrm{MHz}$ and $0.038 \mathrm{MHz}$. Other beam species may be injected with a variety of charge-to-mass ratios and kinetic energies. The longitudinal phase-space area of the injected beam depends upon its mass and kinetic energy per nucleon. This is particularly true for post-stripped beams from the tandem accelerator where the stripper foil thickness and resultant induced energy spread depend on ion species. In fact, most of the $n$ cavity voltage is needed to provide phase space area for injected beams. 


\section{RF Requirements}

For all ion species of interest, the maximum required peak accelerating voltage is $2.5 \mathrm{kV}$ per revolution. A frequency range between $0.2 \mathrm{MHz}$ and 2.7 $\mathrm{MHz}$ is adequate using harmonic numbers between $\mathrm{cne}$ and six. For operation with typical ions in the accelerating mode, the if must tune over most of the available range within a period of about $0.5 \mathrm{~s}$. The frequency must track with the dipole magnetic field of the synchrotron in order to maintain constant beam radius during acceleration.

Given the required accelerating potential, the if system requirements appear to be quite modest. However, the required frequency swing is very large; continuous tuning without band switching is preferred; and the relatively compact accelerator configuration and large aperture $(15 \mathrm{~cm})$ provide little space along the circumference $(1.3 \mathrm{~m})$ for an accelerating sysiem. Vacuum requirements for HISTRAP are such that all beam line vacuum components must withstand baking at $300^{\circ} \mathrm{C}$. Consequently, if system components which are not compatible with the baking process must be thermally isolated from the beam lines.

\section{Prototype cavity}

The selected if cavity configuration has a ferrite-loaded, half-wave coaxial resonator with a single accelerating gap as shown in Fig. 2. The center conductor is concentric with, but completely separate from, the beam line and accelerating gap, except for retractable contact rings that establish electrical contact between the cavity and the accelerating gap as shown in Fig. 3. When vaciuum bake-out of the beam line is required, the contact rings are retracted so that the cavity components are thermally isolated from the beam line. Water 
cooling on the center conductor is provided for removal of both normal if heating and heat radiated from the beam line during bake-out. A second set of contacts on the ends of the cavity is used to suppress $i f$ resonant modes on the beam line.

Characteristics of the cavity are listed in Table 2. The unusually wide tuning range for a single-cavity accelerating system, cavity size limitations, and relatively low frequency result in rather stringent requirements for the ferrite load. Very high permeability is required in order to obtair. the large $r$ tuning range and to minimize the use of extra shunt capacitance for reaching the low end of the tuning range. TDK-type SY7 ferrite, which has been used elsewhere in similar accelerator applications, was selected. SY7 ferrite has a low Curie temperature, $90^{\circ} \mathrm{C}$, and a tendency to become unstable at modera.e if excitation levels, but it should be satisfactory at the power levels required by HISTRAP. The cavity was designed to hold as much ferrite as possible, thus minimizing the if power dissipation per unit of ferrite volume. The ferrite rings are separated by $6.4-\mathrm{mm}$ thick copper rings which are water cooled by peripherally attached copper water lines. The expected ferrite temperature rise under full $r$ excitation is about $5^{\circ} \mathrm{C}$. An array of three individual "figure-eight" bias windings produces up to 3000 ampere turns of bias field in the ferrite in order to swing the permeability from 1400 to 8 . Leads from each half winding are extended out of the cavity through the several ports in the cavity's outer conductor. External connections are used for closing each figure eight and for placing the turns in series or parallel configurations. Space and connection ports are available for up to a total of five turns if more bias excitation is required. 


\section{Prototype test results}

A prototype cavity was designed, fabricated, assembled, and tested. The prototype has only 16 ferrite rings at this time; a number sufficient to check most required characteristics. Figure 4 shows a photograph of the cavity partially assembled with the 16 rings in place. Ferrite specifications for the rings are listed in Table 3. When the cavity is operated with only 16 rings, extra shunt capacitance is requireri to obtain the required tuning range. Consequently, the designed if field intensity level in the ferrite is reached with about half of the normal cavity if voltage.

The ferrite rings were tested individually to determine respective permeability, magnetization, and $\mathrm{f}$ loss characteristics. Typical values of initial permeability are between 2000 and 3000 and $f$ loss characteristics are safely within specification. Measurement of magnetization characteristics was not successful on individual rings due to intrinsic inductances in the test circuit. However, values of permeability calculated from cavity tuning data, shown in Fig. 5, indicate that 3000 ampere turns of bias are sufficient to drive the permeability down to a value of less than eight.

The cavity has operated with if excitation levels up to about $400 \mathrm{~W}$. Excitation to full input power requires a driver system which is not available at this time. Data obtained at the $400-W$ level is shown in Fig. 6 . The shunt resistance of the cavity as seen across the accelerating electrodes is nearly constant throughout the required tuning range at about 80 ohms. Values of $Q$ are directly proportional to frequency and go from less than one at the minimum frequercy to about 10 at the maximum frequency. The low $Q$ characteristic is especially desirable for loading the planned broadband driver amplifier system. At the low end of the tuning range, it is difficult to determine the actual resonant 
frequency, but it is possible to drive the cavity at frequencies substantiaily below resonance. The $Q$ dependence on írequency provides a good compliment for the ferrite magnetization dependence in that $Q$ is lowest in the frequency region where the permeability is the steepest function of bias.

It has been suggested [5] that ferrite instabilities such as the " $Q$ loss" effect can be avoided by keeping the if field-frequency product below $15 \mathrm{mT}$ $\mathrm{MHz}$. For worst case conditions in the HISTRAP cavity, the maximum fieldfrequency product is about $10 \mathrm{mT}-\mathrm{MHz}$.

\section{RF power drive system}

A $20-\mathrm{kW}$ broadband $\mathrm{if}$ power amplifier is planned for driving the HISTRAP cavity. The amplifier is mounted close to the cavity to simplify coupling. Impedance matching is accomplished through the use of an impedance transformer. The if drive signal is derived from a programmable frequency synthesizer. Bias current for the cavity's ferrite will be obtained from a programmable dc power supply. Analog programming signals for both the synthesizer and the bias power supply are derived from a Hall field probe in one of the eight dipole magnets. A diagram of the controls for the if system is shown in Fig. 7.

The $n$ controls are based upon the use of a frequency synthesizer which is capable of switching frequency in about a microsecond in response to variations in digital frequency information (at least one such synthesizer is commercially available). An analog-to-digital converter derives a reference frequency from the Hall probe signal produced in one of the dipole magnets. Feedbar loops with signals derived from beam position and phase provide reference frequency updating between ADC sampling cycles. 


\section{Summ.ary}

The feasibility of uperating an $n$ cavity with the tuning range required by HISTRAP was demonstrated. Characteristics of the cavity were measured. Deveiopment of appropriate tuning and drive circuitry is under way. Demonstration of cavity operation ai full $\mathrm{r}$ power will be attempted when a larger power amplifier becomes available.

\section{References}

[1] S. W. Mosko et al., Proc. of the 1989 IEEE Part. Acceil. Conf., pp. 193.

[2] [. K. Olsen et al., Nucl. Instr. and Meth. B24/25 (1987) 26.

[3] B. A.. Tatum et al., Proc. of the 1989 IEEE Part. Accel. Conf., pp. 393.

[4] J. W. Johnson et al., J. Vac. Sci. Technol. A 7 (3) (May/June 1989) 2430.

[5] M. L. Plotkin, private communication. 


\section{Figure captions}

Fig. 1. A plan view of HISTRAP showing its injection beam line with an ECR source on the left, a transier line from the tandem, and an extracted ion beam line on the right.

ORNL DWG 87-6616

Fig. 2. A cutaway longitudinal view and an end view of the HISTRAP if cavity. ORNL DWG $87 \cdot 17429 R$

Fig. 3. A sectional view of the accelerating gap showing the gap insulator and the contact rings between the cavity and the beam line. ORNL DWG 89-5885

Fig. 4. A phoiograph of the if cavity with the top half of the outer conductor raised. The 16 ferrite rings are in place with their cooling plates interspaced. Vacuum capacitors are connected across the accelerating gap. ORNL PHOTO 10257-88

Fig. 5. Relative permeability oi the SY7 ferrite rings as a function of toroidal dc excitation.

ORNL DWG 88-16550

Fig. 6. Cavity " $Q$ " and shunt resistance as a function of frequency. ORNL DWG 88-16551 
Fig. 7. A block diagram of the $f$ system controls showing the primary reference frequency source and feedback loops for fine tuning. Additional feedback loops are required for cavity tuning and amulitude control.

ORNL DWG 90-15601 
Table 1

Accelerator Parameters

Circuniference

Maximum Rigidity

Dipole Magnets

Quadrupole Magnets

Accelerating Sectors

Vacuum System - Base Pressure
46.8 meters

2.67 Tesla meteis

\section{8}

12

1

10-11 Torr 


\section{Table 2}

RF cavity characteristics

Peak ri voltage

Tuning range

Overall length

Beam tube diameter

Center conductor OD

Outer conductor ID

Ferrite rings

Material

ID

OD

Thickness

Rings per cavity

Ferrite cooling

Peak power density in ferrite

Ferrite permeability range

Peak ferrite bias current

Shunt capacitance required

Total peak cavity if drive power
2500 volts

0.2 to $2.7 \mathrm{MHz}$

1.2 meters

0.15 meters

0.254 meters

0.648 meters

TDK SY7 (NiZn)

0.3 meters

0.5 meters

0.025 meters

28

water-cooled Cu separators

$2000 \mathrm{~mW} / \mathrm{cc}$

8 to 1400

3000 ampere turns

$6000 \mathrm{pF}$

$20 \mathrm{~kW}$ 


\section{Table 3}

Ferrite specifications

Initial permeability

RF excitation loss at $0.2 \mathrm{MHz}$ and 275 gauss if field

RF excitation ioss at $2.5 \mathrm{MHz}$

and 22 gauss if field

$$
\begin{array}{r}
2500 \\
<0.06 \text { W/Cc } \\
<0.06 \text { W/ce }
\end{array}
$$




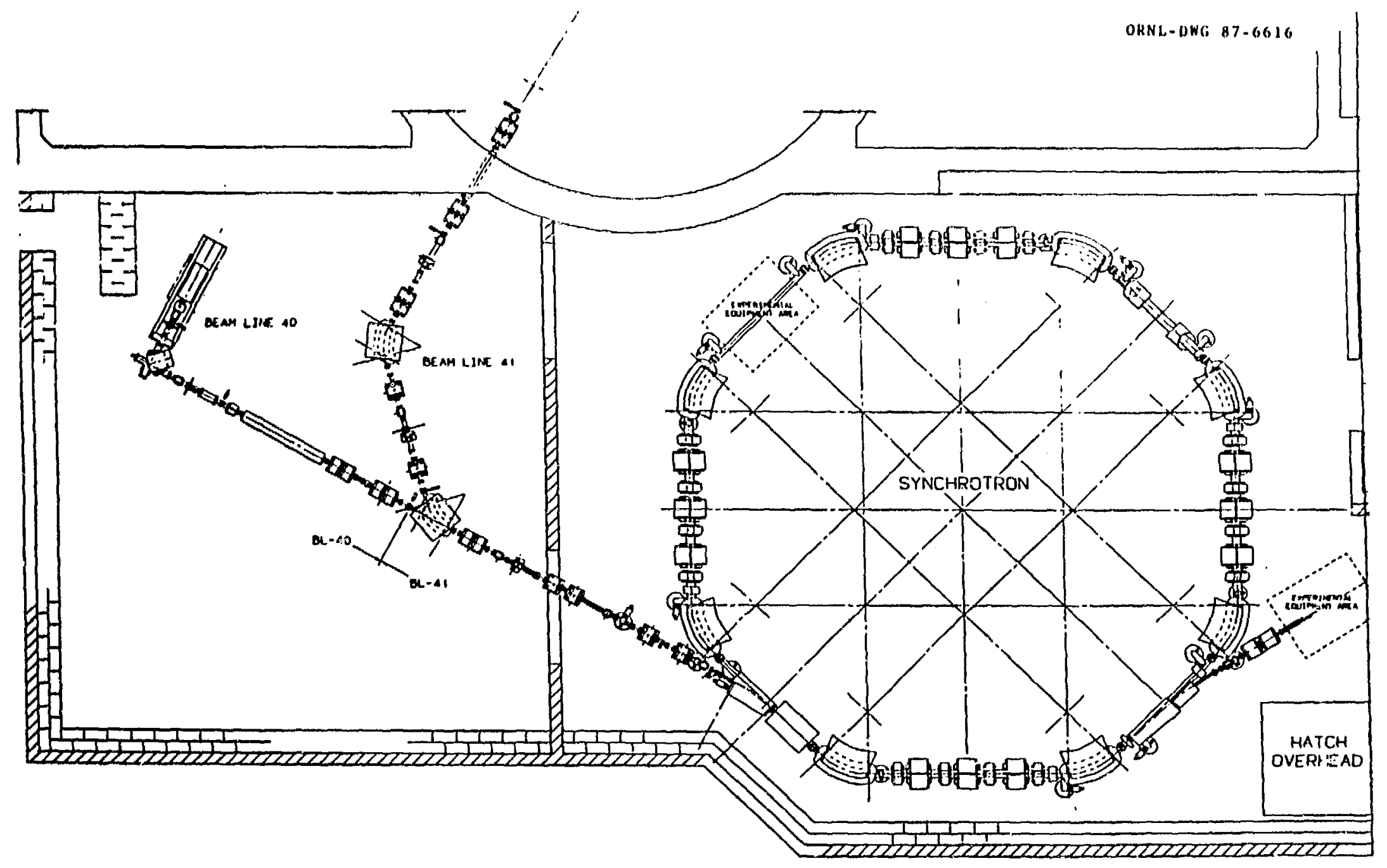




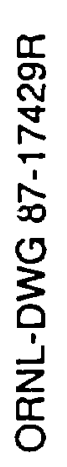

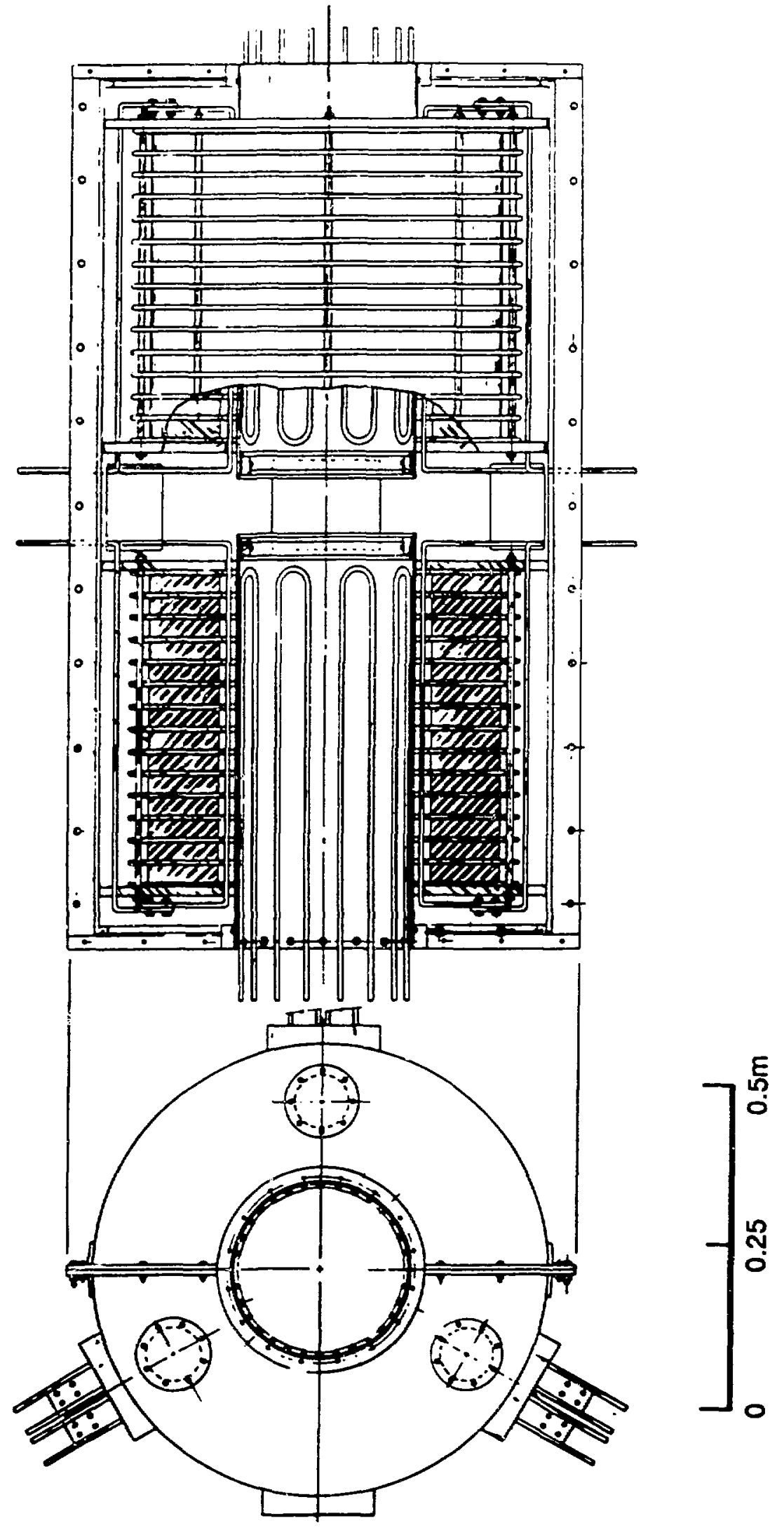




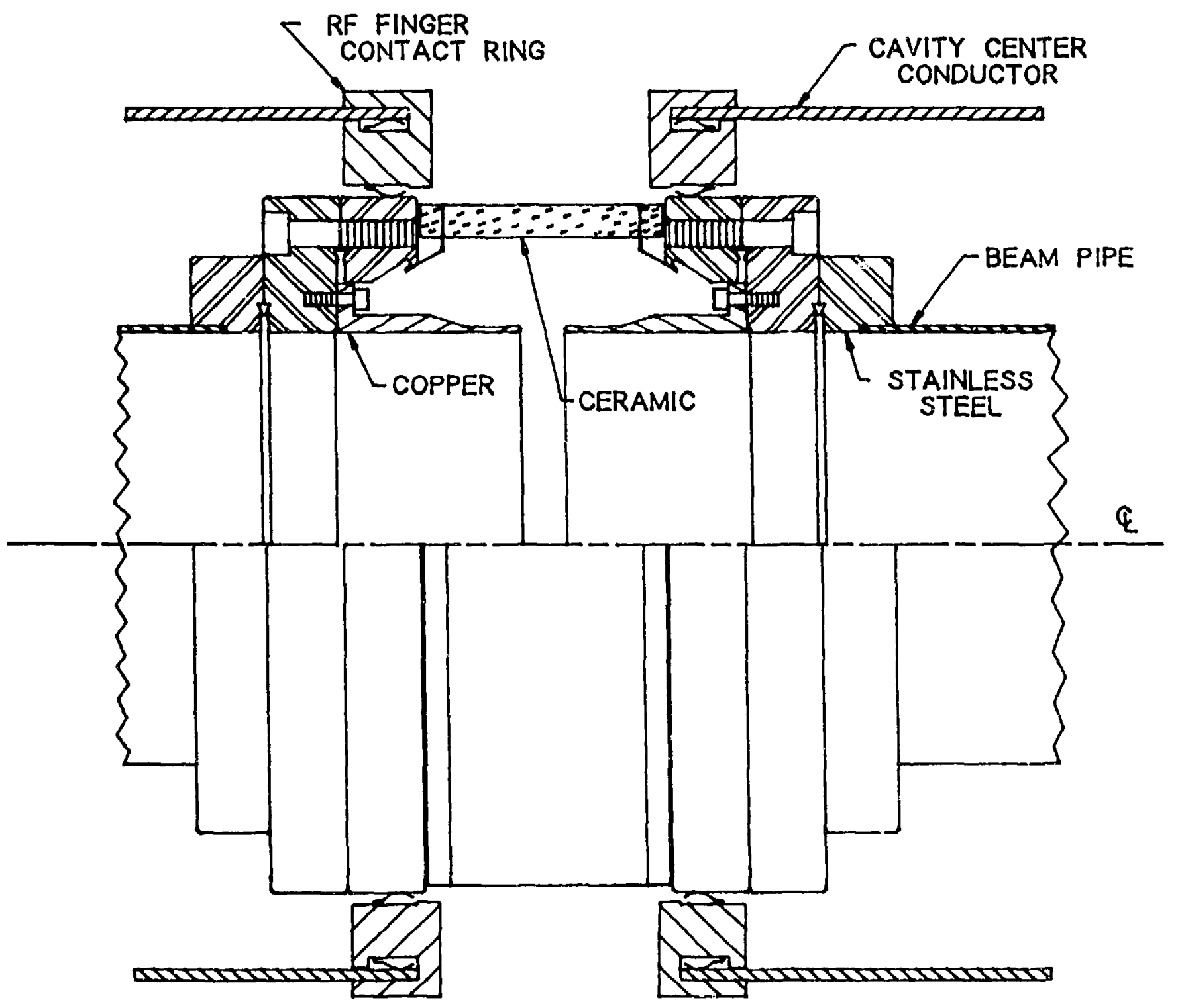




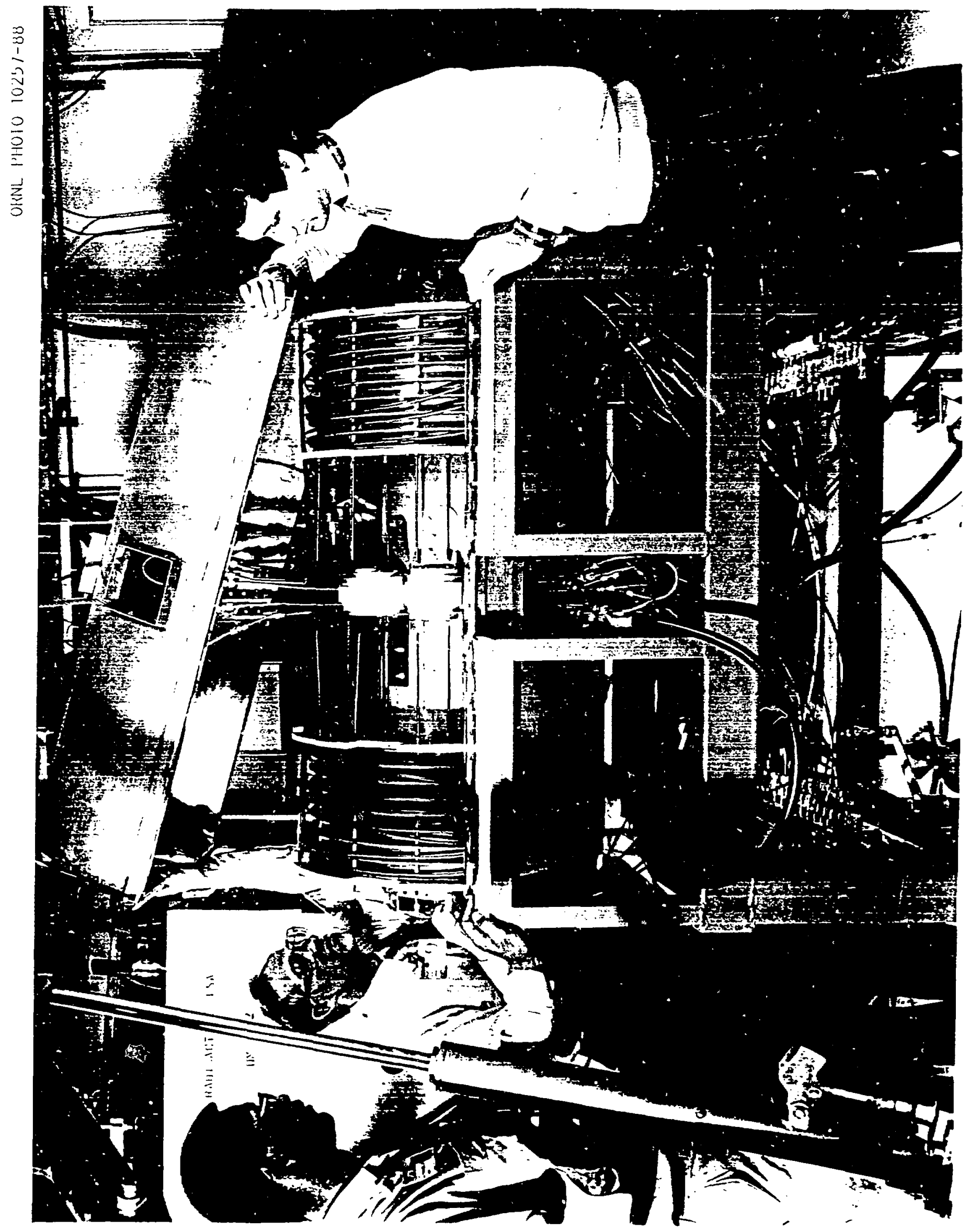




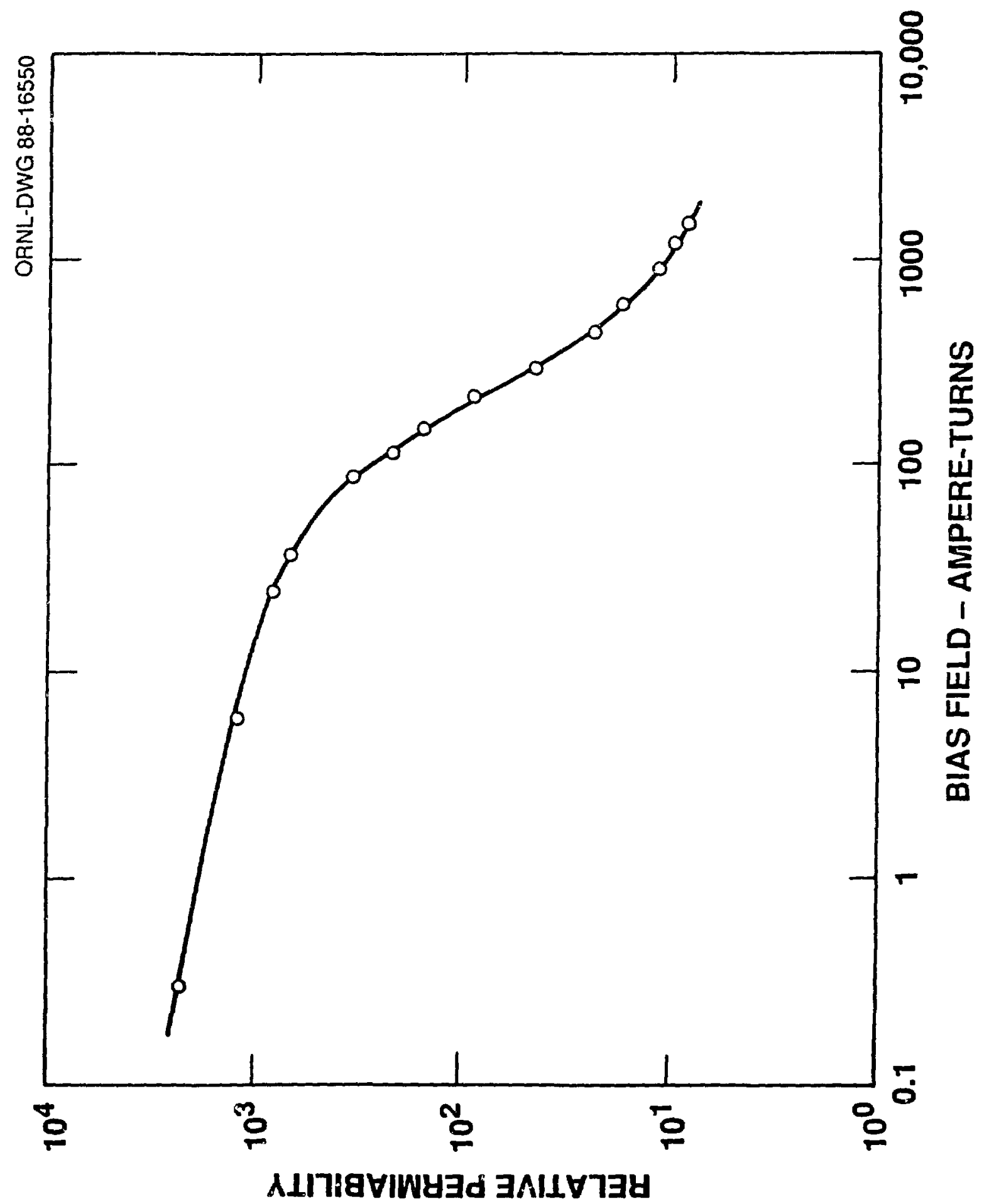


ORNL-DWG 88-16551

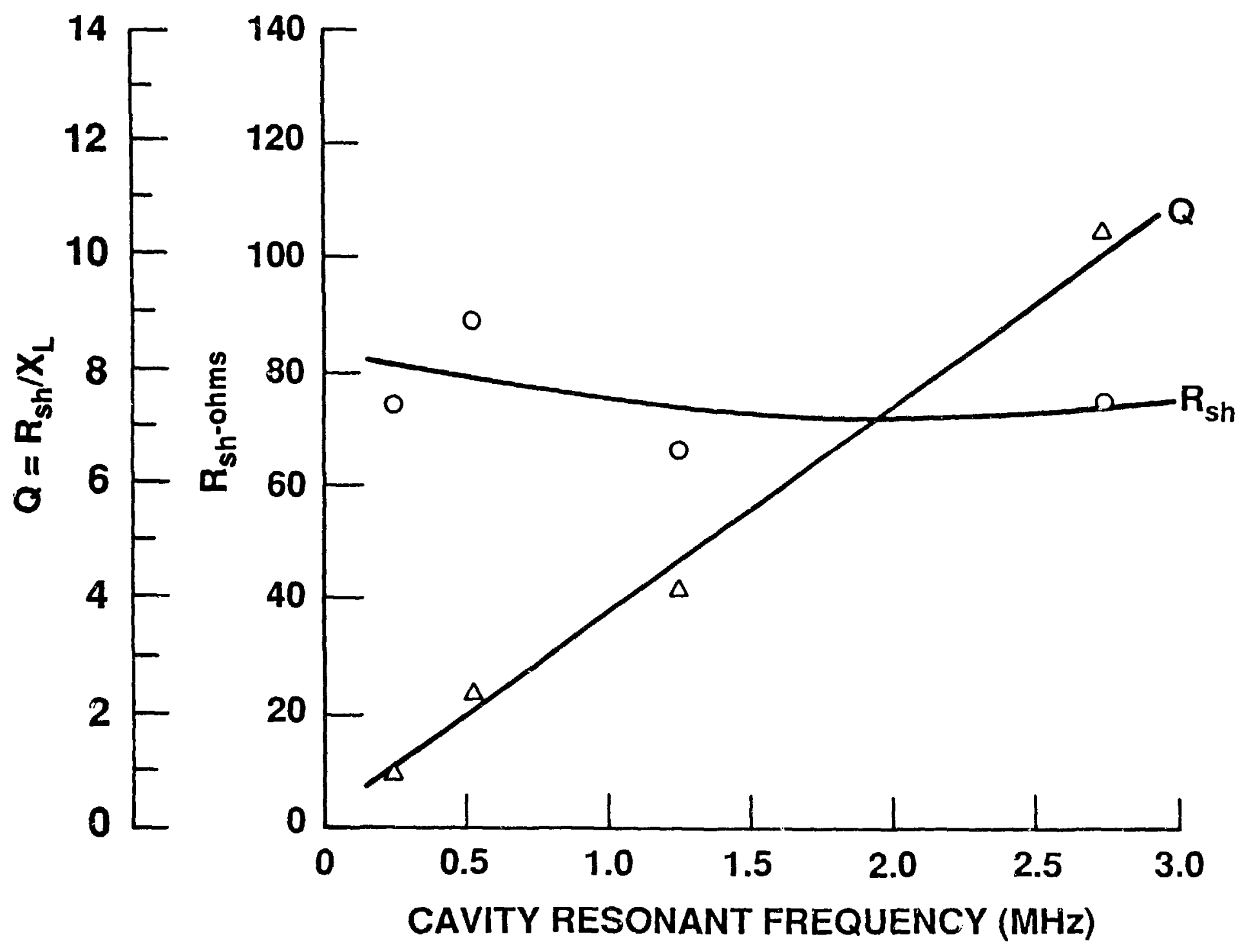




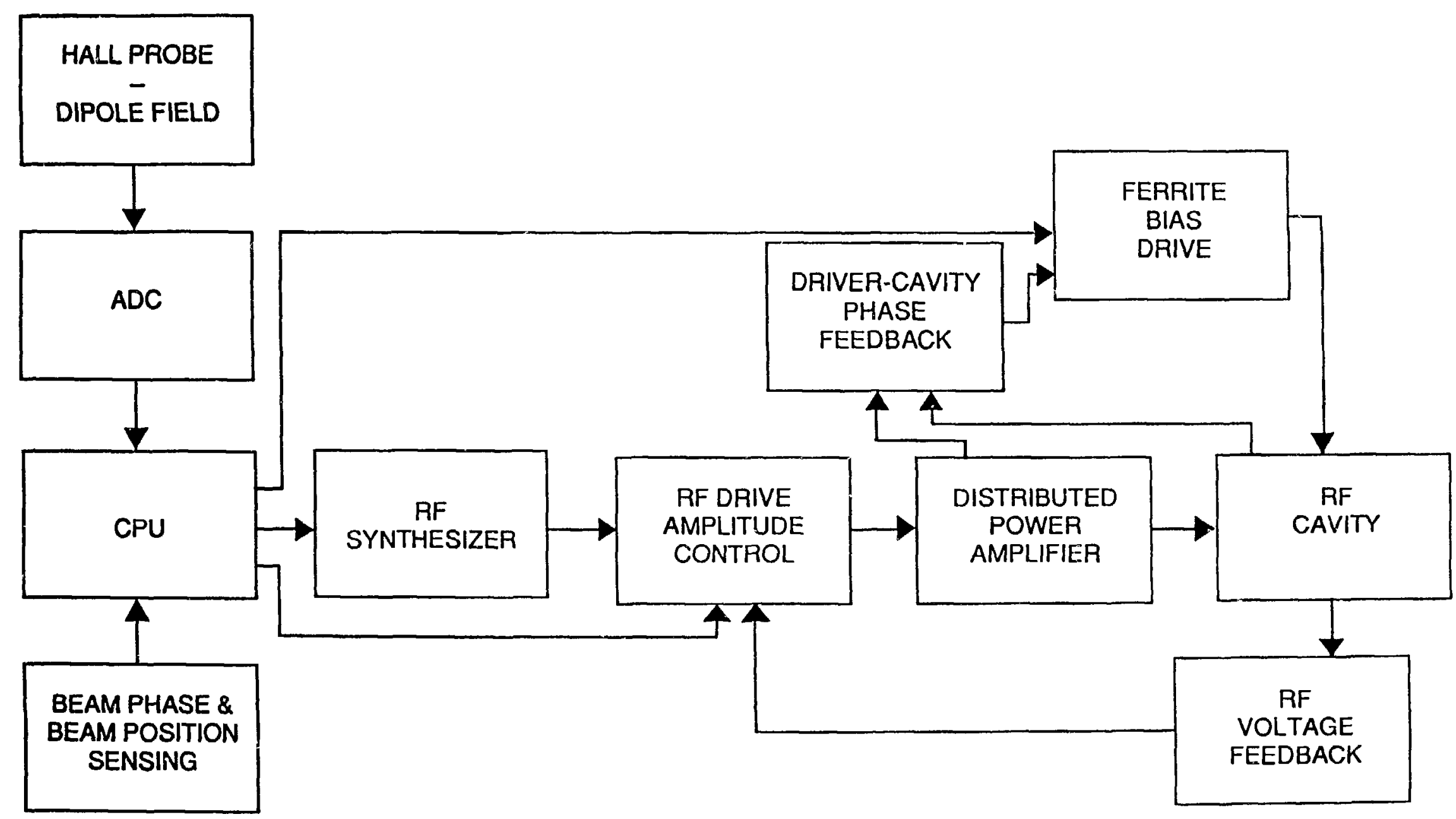

